\title{
Las formas de la violencia
}

\author{
Xavier Crettiez \\ Argentina: Waldhuter, 2009. \\ Reseña escrita por Julián Pérez Ortiz* \\ * Instituto Caro y Cuervo, Bogotá, Colombia. Magíster en Literatura y Cultura
}

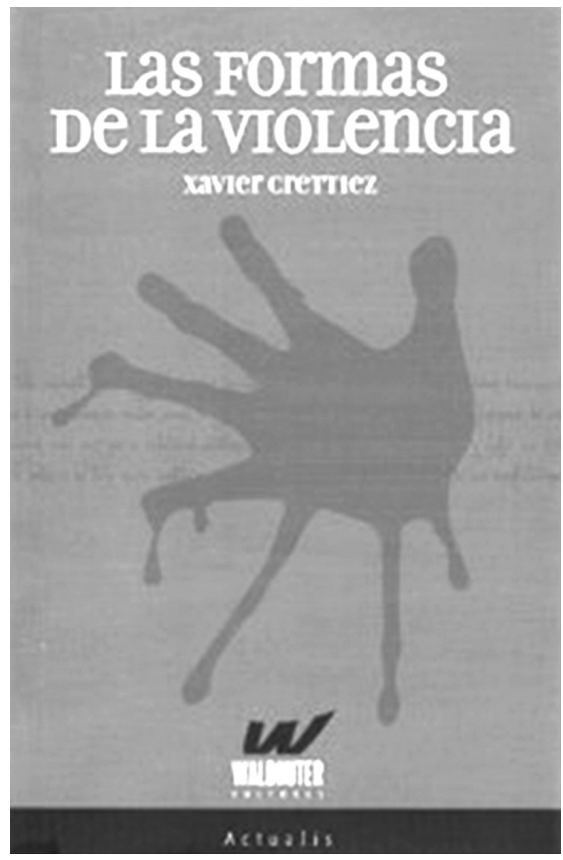

Reseña. Este libro es una propuesta para estudiar las formas singulares de los fenómenos violentos. El autor parte del supuesto que afirma que si bien es imposible aceptar como sucesos iguales los diversos acontecimientos que el sentido común clasifica bajo el rótulo de violencia, entonces lo primero para llevar a cabo una interpretación adecuada es negarse a pensarlos en la forma de un solo concepto generalizador que los agrupa en un vocablo singular, como si todos pertenecieran a esa única categoría. Por eso, lo más adecuado es aceptar la concepción plural de violencias, ya que el término representa más certeramente las realidades particulares cuya esencia es su forma sin igual. En ese sentido, no existe la violencia: existen las violencias. Puesto lo anterior, Crettiez propone las tipologías básicas que el estudioso de la violencia debe dominar para cualificar la realidad del hecho si quisiera demostrarlo como violento. Estás consisten en determinar si el fenómeno es: 1) una forma de violencia física: aquella en que alguien entendido como un individuo, grupo o Estado ejerce coerción y daño concreto en la realidad empírica de otro, es decir, su cuerpo o sus bienes; 2) una forma de violencia simbólica: aquella que funciona a través de un actuar sistemático que, previendo todas las consecuencias, diseńa una estructura para justificarse como normal dentro de los procesos de socialización y culturización de los individuos de un Estado; 3) una forma de violencia política: que se refiere a un actuar inadecuado que tiene su causa dentro 
del campo gubernamental; y 4) una forma de violencia social: referente a las violencias físicas y simbólicas que acontecen en la vida espontánea y domestica de los individuos de un Estado.

Ahora bien, el propósito de establecer estas tipologías no significa que solo existan cuatro clases de violencias, ya que una lectura de la realidad puede demostrar dos cosas: una, que al interior de cada tipología hayan modos de expresión completamente diferentes y, dos, que un mismo fenómeno puede acontecer a través de una forma de violencia que es a la vez física, simbólica, política y social. Así, la lectura más adecuada del fenómeno violento dependerá del dominio que el estudioso de la violencia posea para utilizar estos criterios en el momento de interpretar un suceso violento determinado.

A partir de esa recomendación, Crettiez comenzará a desplegar, por un lado, un amplio espectro de violencias (como por ejemplo, la violencia contingente al orden social ordinario; la violencia inherente a la acción y al sistema político; y la violencia de dimensión identitaria) a la vez que sugiere maneras de pensar sobre las mismas (por ejemplo, si se percibe que la violencia es una realidad repudiada, o si puede pensarse como una acción liberadora, o también si puede ser considerada como algo ineludible a las formas de vida de los seres humanos).

Como puede verse, la propuesta de lectura de los fenómenos violentos que el autor diseña no se limita a calificar el hecho violento de acuerdo con valorizaciones positivas o negativas. Más bien, ha sido configurada con el propósito de aportar a los lectores una posibilidad para interpretar realidades trabajadas de muchas maneras justamente porque, quiérase o no, son inherentes al ser humano y los grupos sociales en todo el sentido del término.

Expresado esto, las reflexiones globales que componen el texto están organizadas en cuatro capítulos, todos orientados con base en un criterio esencial que el estudioso de la violencia debe tener para leer cualquier fenómeno violento: identificar el tipo de actor que la ejerce, sobre quién la usa y para qué lo hace.

El primero es "Los procesos de adhesión a la violencia", donde el autor desarrolla una reflexión que considera los móviles por los cuales alguien (sea un individuo o un grupo) decide hacerse violento. Las fuentes que utiliza para demostrar sus tesis son, por supuesto, registros históricos de Occidente y América, localizados en épocas específicas. De esa manera, supone que circunstancias como la marginalidad política, la frustración económica e, incluso, las características culturales propias de muchos grupos son condiciones o criterios que legitiman el uso de la violencia. En su reflexión Crettiez amplía la concepción de los fenómenos violentos ya que convence que no siempre son asumidos como un recurso al cual apelar por necesidad. Pueden ser también los rasgos de una identidad social, la acciones de un sistema de organización estatal y también formas aceptadas o no por algunas visiones culturales para satisfacer placeres u obtener reconocimientos.

En el segundo capítulo, "Violencias sociales y violencia de Estado: las lógicas de la violencia en democracia", sustenta cómo pueden funcionar los fenómenos violentos dentro de las democracias modernas. La primera es la violencia del Estado que se refiere a la manera como los poderes estatales deciden practicar la violencia con el propósito de hacer valer un orden o cumplir una voluntad específica. La segunda, que podría estar correlacionada con la anterior, es la violencia contra el Estado, en donde identifica tres agentes que la llevan a cabo: 1) los movimientos sociales y el sindicalismo; 2) las organizaciones de lucha armada que la mayoría de las veces son rotuladas 
como "grupos terroristas"; y 3) la violencia urbana. Por último, las violencias interindividuales, donde considera el papel del Estado frente a las violencias acontecidas en el ámbito cotidiano de sus ciudadanos.

El tercer capítulo, "Violencias de masa y de aterrorización: reflexiones sobre las violencias extremas", Crettiez articula una lectura que se puede hacer de las violencias teniendo como eje articulador el concepto de masacre vinculado al de horror. Sobre la base que ofrecen los capítulos anteriores, cuestiona cuáles podrían ser los motivos que incitan a los seres humanos a decidirse por formas violentas aterradoras, como por ejemplo el apoyo de las autoridades políticas para ejecutar civiles, el silencio de la comunidad internacional ante el crimen en masa o la puesta en escena de un espacio clausurado para llevar a cabo actos inhumanos de tortura. En este punto, se explica cómo las violencias son actos que estimulan el placer de los verdugos o el cumplimiento cabal de ideologías.

Finalmente, en el cuarto capítulo, "Las metamorfosis de la violencia", reflexionará cómo en las últimas décadas se ha percibido un cambio en las formas de representar las violencias. El estado y sus instrumentos perfomativos (los medios de comunicación) construyen realidades donde se puede vislumbrar no solo una crítica a las violencias sino un habituarse a las mismas, con lo que se crean condiciones en las cuales ya es aceptable encontrar mercados disponibles para la guerra.

El autor cierra su trabajo reafirmando lo dicho al principio: no puede hablarse de violencia sino de violencias y, por eso mismo, sugiere a los lectores ampliar su sistema de lectura de los fenómenos violentos argumentando que es necesario abordar el problema desde una articulación de perspectivas referentes a los diversos campos de estudio. 